\title{
Butyronitrile-Based Electrolyte for Dye-Sensitized Solar Cells
}

\author{
Frédéric Sauvage, ${ }^{*,+, \neq}$ Sarine Chhor, ${ }^{\dagger}$ Arianna Marchioro, ${ }^{\dagger}$ Jacques-E. Moser, ${ }^{\dagger}$ and Michael Graetzel ${ }^{*,+}$ \\ ${ }^{\dagger}$ Laboratoire de Photonique et Interfaces, Institut des Sciences et Ingénierie Chimiques, Ecole Polytechnique Fédérale de Lausanne, \\ Station 6, CH-1015 Lausanne, Switzerland \\ ${ }^{\ddagger}$ Laboratoire de Réactivité et Chimie des Solides, Université de Picardie Jules Verne, CNRS UMR6007, 33 rue Saint-Leu, \\ F-80039 Amiens Cedex, France
}

Supporting Information

ABSTRACT: We elaborated a new electrolyte composition, based on butyronitrile solvent, that exhibits low volatility for use in dye-sensitized solar cells. The strong point of this new class of electrolyte is that it combines high efficiency and excellent stability properties, while having all the physical characteristics needed to pass the IEC 61646 stability test protocol. In this work, we also reveal a successful approach to control, in a sub-Nernstian way, the energetics of the distribution of the trap states without harming cell stability by means of incorporating $\mathrm{NaI}$ in the electrolyte, which shows good compatibility with butyronitrile. These excellent features, in conjunction with the recently developed thiophene-based

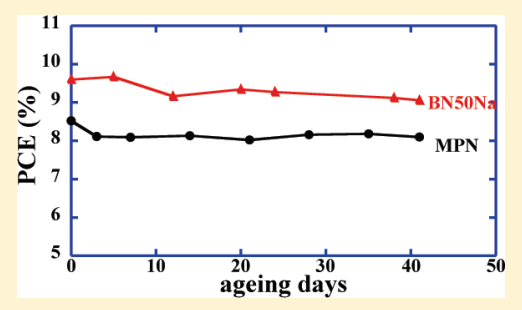
C106 sensitizer, have enabled us to achieve a champion cell exhibiting $10.0 \%$ and even $10.2 \%$ power conversion efficiency (PCE) under 100 and $51.2 \mathrm{~mW} \cdot \mathrm{cm}^{-2}$ incident solar radiation intensity, respectively. We reached $>95 \%$ retention of PCE while displaying as high as $9.1 \% \mathrm{PCE}$ after $1000 \mathrm{~h}$ of $100 \mathrm{~mW} \cdot \mathrm{cm}^{-2}$ light-soaking exposure at $60{ }^{\circ} \mathrm{C}$.

\section{INTRODUCTION}

Dye-sensitized solar cells (DSCs) are electrochemical devices comprising a light-absorbing molecule anchored onto semiconducting nanoparticles, which make use of sunlight to generate electricity. ${ }^{1}$ One distinction of this photovoltaic (PV) technology lies in the separation of the two basic processes responsible for, on the one hand, photocurrent generation through exciton dissociation and, on the other hand, charge transport. DSCs are also a disruptive type of PV device for two aspects. First, in contrast to silicon technology, surface/point defects play an essential role, since they induce the formation of sub-band-edge states whose energy and distribution govern the rates of charge injection, transport, and back-reaction. ${ }^{2,3}$ Second, the principle of DSCs relies on electrochemical processes associated with a soluble redox couple, e.g., $\mathrm{I}_{3}{ }^{-} / \mathrm{I}^{-}$, that ensures the regeneration of the oxidized dye by hole transfer to iodide. ${ }^{4}$ The motivation to introduce DSCs into the PV market results from a set of specific advantages: its short energy payback ( $<1$ year), lower greenhouse gas emission, and potential low-cost solar electricity generation owing to the cheap constituents and simple manufacturing requirements. ${ }^{5}$ This is also a versatile technology that comes in flexible, ${ }^{6-8}$ transparent, $^{9}$ or bifacial ${ }^{10}$ embodiments, paving the way toward new applications such as integrated smart windows for buildings. On the laboratory scale (cell area of $\sim 0.2 \mathrm{~cm}^{2}$ ), power conversion efficiency (PCE) above 11\% has been achieved using either the so-called panchromatic black dye N749 ${ }^{11}$ or the heteroleptic bipyridine $\mathrm{Ru}$ (II) red dyes based on thiophene units, ${ }^{12-15}$ or more recently by means of the zinc porphyrin dye coded YD2. ${ }^{16}$ In modules, 10\% PCE has recently been disclosed, thus demonstrating once more DSC's competitiveness. ${ }^{17}$
However, to date, PCEs extending into double digits were reached only in association with volatile electrolytes (i.e., acetonitrile-based), which hampers cell stability during the standard accelerated protocol tests. Research aiming at elaborating alternatives to acetonitrile has identified various options, ranging from nonvolatile electrolytes based on 3-methoxypropionitrile ${ }^{18}$ and gel-type electrolytes ${ }^{19-21}$ to binary or ternary eutectic melt solvent-free ionic liquids; ${ }^{22,23}$ unfortunately, for the latter their higher viscosities harm $\mathrm{I}_{3}^{-} / \mathrm{I}^{-}$mass transport. For the most efficient dyes, reported PCEs were $\sim 8.2 \%$ with $\mathrm{K} 77$ and $\mathrm{B} 11,{ }^{14,18}$ $8.5 \%$ with $\mathrm{C}_{103}{ }^{24}$ and $9.3 \%$ with $\mathrm{C}_{106}{ }^{25}$ after $1000 \mathrm{~h}$ of exposure under combined light and thermal stress $\left(60^{\circ} \mathrm{C} / 100 \mathrm{~mW} \cdot \mathrm{cm}^{-2}\right.$ illumination).

With the goal of reducing the efficiency gap when going from volatile to nonvolatile solvent, we have optimized in this work a new, better performing family of low-volatility electrolytes based on butyronitrile solvent whose physical specifications should render it suitable to satisfy the IEC 61646 protocol for accelerated stability tests (i.e., melting point, $-112{ }^{\circ} \mathrm{C}$; boiling point, $+118{ }^{\circ} \mathrm{C}$ ). Taking advantage of the recently developed polypyridyl $\mathrm{Ru}(\mathrm{II})$ complex, $\mathrm{Na}-\mathrm{Ru}\left(4,4^{\prime}\right.$-bis(5-hexylthio)thiophen-2-yl)-2,2'-bipyridine)-4-carboxylic acid-4'-carboxylate- $2,2^{\prime}$ bipyridine)(thiocyanate) ${ }_{2}$, coded $\mathrm{C} 106$, we achieved with the new formulations $>10 \%$ conversion efficiency while demonstrating outstanding PCE retention upon light-soaking and $60{ }^{\circ} \mathrm{C}$ thermal stress.

Received: April 15, 2011

Published: June 27, 2011 


\section{RESULTS AND DISCUSSION}

Photovoltaic experiments employed the new sensitizer C106 developed by Wang et al., ${ }^{13}$ the structure of which is shown below:

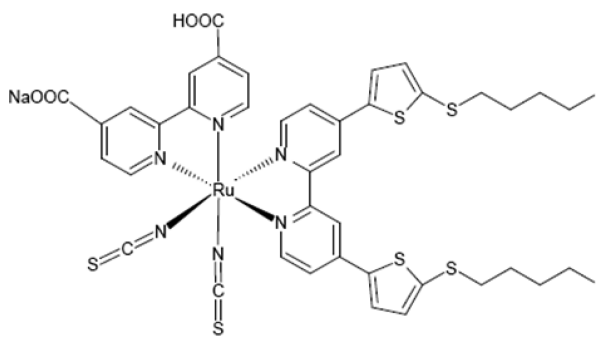

Prior to incorporating the new electrolytes within a complete DSC device, fluorine-tin oxide (FTO)-Pt symmetric cells were assembled to measure the electrolyte's intrinsic characteristics, namely the charge-transfer resistance on Pt-supported FTO electrode and the tri-iodide diffusion coefficient. These two kinetic parameters were assessed by means of electrochemical impedance spectroscopy (EIS), which allows discrimination of the different electrochemical processes according to their relaxation time constants. With this configuration, the resulting EIS spectrum features two main contributions besides the resistance from contacts, cables, transparent conducting oxide (TCO), etc. (Figure 1a, inset). The first component, depicting a semi-arc in the highfrequency region, arises from the charge-transfer resistance of the redox species at the FTO-Pt interface coupled with the doublelayer capacitance at this same interface. At lower frequencies, a second arc arises from a finite Nernst impedance attributed to the diffusion of tri-iodide in electrolyte. The entire spectrum was simulated using the equivalent electrical model shown in the Figure 1a inset to accurately determine the values corresponding to the charge-transfer resistance $\left(R_{\mathrm{CT}}\right)$ and the tri-iodide diffusion coefficient $\left(D_{\mathrm{I}_{3}}{ }^{-}\right)$. The latter parameter is extracted from the following relationship:

$$
D_{\mathrm{I}_{3}-}=\delta^{2} K_{N}
$$

where $\delta$ represents half the distance between the two electrodes $(\delta=10 \mu \mathrm{m})^{26}$ and $K_{N}$ is deduced from the ion diffusion impedance, $^{27}$

$$
Z_{N}=\frac{W}{\sqrt{i \omega}} \tanh \left(\sqrt{\frac{i \omega}{K_{N}}}\right)
$$

In the second equation, $\omega$ represents the angular frequency (in $\mathrm{rad} \cdot \mathrm{s}^{-1}$ ) and $W$ the Warburg parameter. As a result, using rigorously the same composition as that in the optimized electrolyte based on 3-methoxypropionitrile (MPN) solvent [1 $\mathrm{M}$ 1,3-dimethylimidazolium iodide (DMII), $0.15 \mathrm{M} \mathrm{I}_{2}, 0.5 \mathrm{M}$ $\mathrm{N}$-butylbenzimidazole (NBB), and $0.1 \mathrm{M}$ guanidinium thiocyanate (GuNCS)], we obtained in the case of the butyronitrile (BN) solvent $R_{\mathrm{CT}}=1.4 \Omega \cdot \mathrm{cm}^{2}$ and $D_{\mathrm{I}_{3-}}=4.6 \times 10^{-5} \mathrm{~cm}^{2} \cdot \mathrm{s}^{-1}$. This is equivalent to the charge-transfer resistance obtained in MPN, but with almost a 2 times lower tri-iodide diffusion coefficient $\left(D_{\mathrm{I}_{3^{-}}}=\right.$ $\left.2.5 \times 10^{-5} \mathrm{~cm}^{2} \cdot \mathrm{s}^{-1}\right)$. Part of this improved mass transport arises from the lower viscosity of the BN-based electrolyte, in agreement with the Stokes-Einstein relationship $\left(\eta_{\mathrm{MPN}}=3.0\right.$ cps vs $\left.\eta_{\mathrm{BN}}=2.3 \mathrm{cps}\right)$. These symmetric cells were stored for 42 days $(\sim 1000 \mathrm{~h})$ at $60^{\circ} \mathrm{C} / 100 \mathrm{~mW} \cdot \mathrm{cm}^{-2}$ conditions to verify
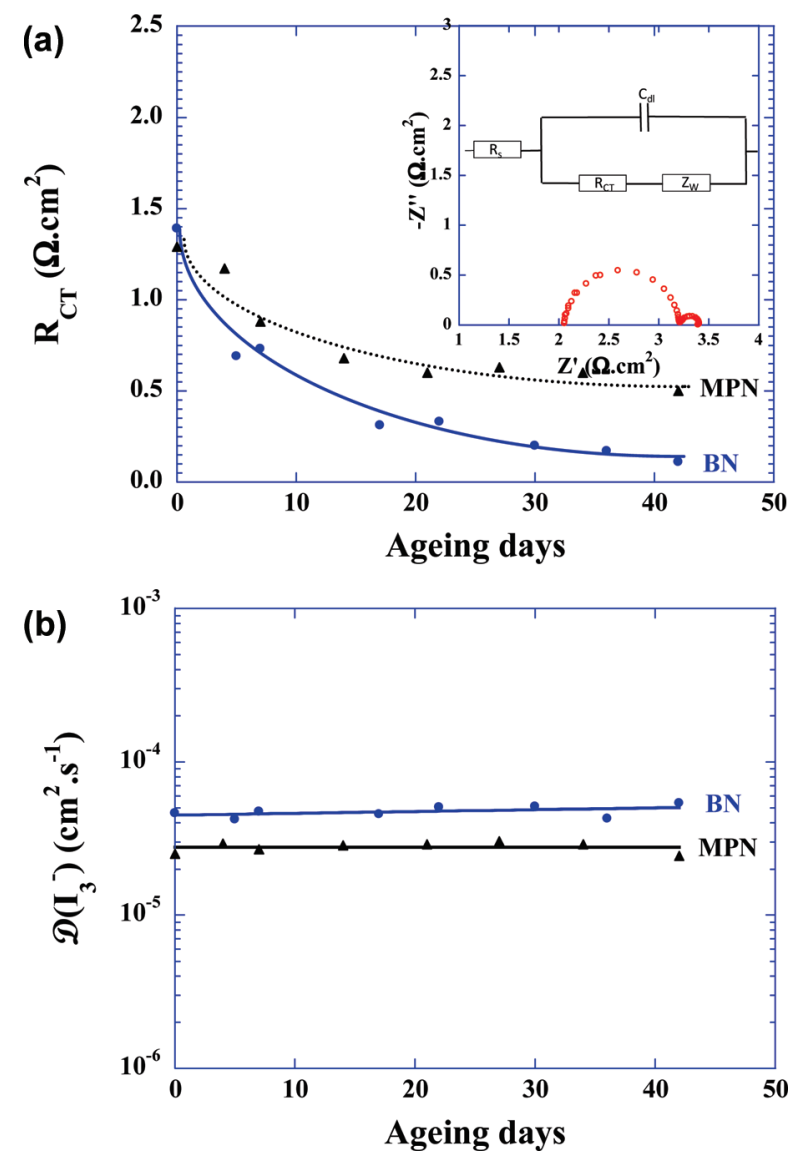

Figure 1. Evolution of the charge-transfer resistance (a) and tri-iodide diffusion coefficient (b) as a function of time of aging $\left(60{ }^{\circ} \mathrm{C}-\right.$ $100 \mathrm{~mW} \cdot \mathrm{cm}^{-2}$ illumination) for MPN and BN electrolyte (1 M DMII, $0.15 \mathrm{M} \mathrm{I}_{2}, 0.5 \mathrm{M} \mathrm{NBB}, 0.1 \mathrm{M}$ GuNCS). The inset shows a typical impedance spectrum recorded on a TCO-Pt symmetric cell and the equivalent electrical circuit used to extract the kinetic parameters.

the intrinsic stability of the electrolyte as well as to attest to its good electrochemical stability with respect to the $\mathrm{Pt}-\mathrm{TCO}$ interface. During the course of this accelerating protocol, two features were noted. First, the charge-transfer resistance at the surface of the Pt electrode decreases with time, regardless of the solvent, to attain a steady value after $\sim 40$ days. This drop is more pronounced with the $\mathrm{BN}$ electrolyte, which attains $R_{\mathrm{CT}}=$ $0.1 \Omega \cdot \mathrm{cm}^{2}$ in comparison to $0.5 \Omega \cdot \mathrm{cm}^{2}$ for the MPN electrolyte. It appears that the electrocatalytic activity of the platinum nanoparticles for tri-iodide reduction increases during this thermal/ light treatment. A complementary set of experiments with temperature under darkness suggests that this behavior is related to heat rather than light (Supporting Information, Figure S1). Furthermore, we also highlight the role of the GuNCS additive used in the electrolyte formulation, which acts to stabilize the $\mathrm{TCO}-\mathrm{Pt}$ /electrolyte interface. Indeed, for electrolyte composition free of GuNCS, the $R_{\mathrm{CT}}$ value increased markedly upon thermal/light storage to $>200 \Omega \cdot \mathrm{cm}^{2}$ for the BN composition and even $>500 \Omega \cdot \mathrm{cm}^{2}$ in the case of the MPN electrolyte. Most likely in relation with this drastic increase of charge-transfer resistance, we also observed, after aging, vanishing of the darkish color due to the platinum nanoparticles at the location where the TCO surface was in direct contact with the electrolyte. As a consequence, the guanidinium cation, which is used to maintain 

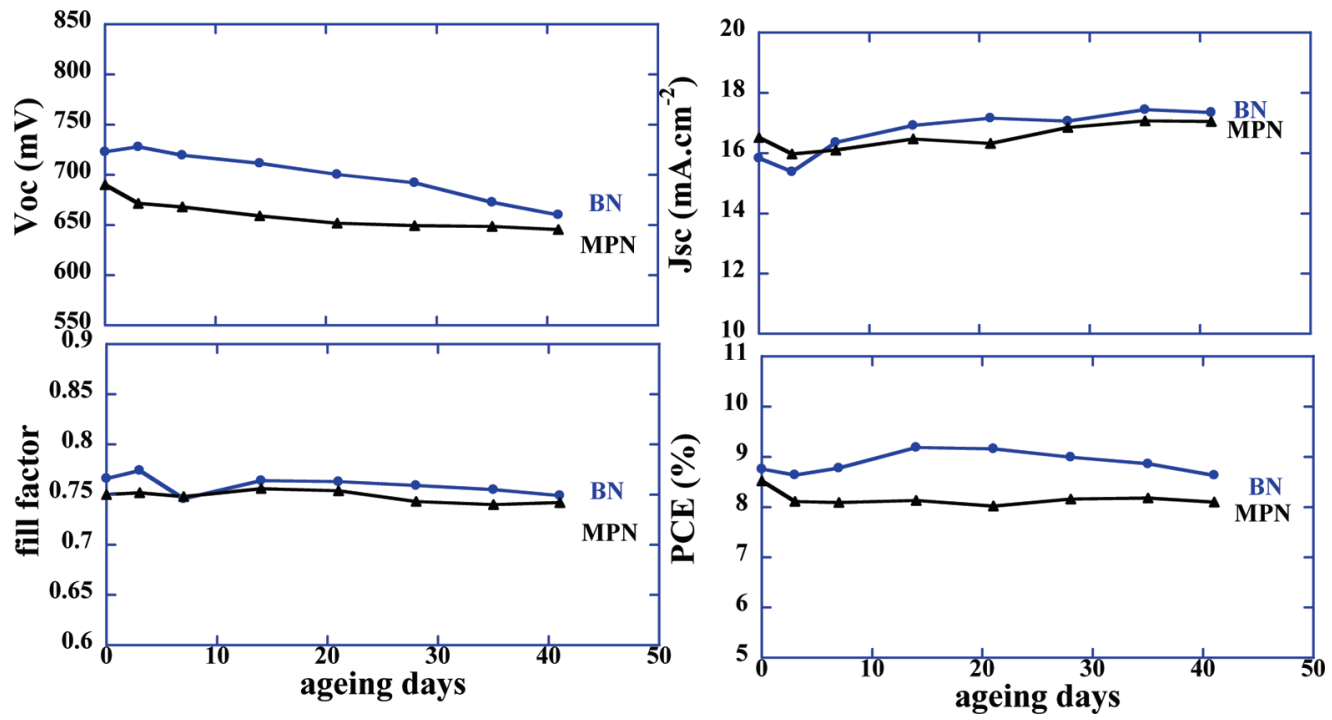

Figure 2. Evolution of the cell characteristics $\left(V_{\mathrm{oc}} J_{\mathrm{sc}} \mathrm{ff}\right.$, and PCE) as a function of aging time $\left(60^{\circ} \mathrm{C} / 100 \mathrm{~mW} \cdot \mathrm{cm}^{-2}\right.$ illumination $)$ for MPN and BN electrolytes (1 M DMII, $0.15 \mathrm{M} \mathrm{I}_{2}, 0.5 \mathrm{M} \mathrm{NBB}, 0.1 \mathrm{M}$ GuNCS).

Table 1

\begin{tabular}{|c|c|c|c|c|c|c|}
\hline & \multicolumn{6}{|c|}{ aging time } \\
\hline & \multicolumn{2}{|c|}{$t=0 \mathrm{~h}$} & \multicolumn{2}{|c|}{$t=\max \mathrm{PCE}$} & \multicolumn{2}{|c|}{$t=1000 \mathrm{~h}$} \\
\hline & MPN & $\mathrm{BN}$ & MPN & $\mathrm{BN}$ & MPN & $\mathrm{BN}$ \\
\hline$V_{\mathrm{oc}}(\mathrm{mV})$ & 690 & 723 & - & 712 & 646 & 660 \\
\hline$J_{\mathrm{sc}}\left(\mathrm{mA} \cdot \mathrm{cm}^{-2}\right)$ & 16.5 & 15.8 & - & 16.9 & 17.1 & 17.4 \\
\hline $\mathrm{ff}$ & 0.75 & 0.77 & - & 0.76 & 0.74 & 0.75 \\
\hline$\eta(\%)$ & 8.5 & 8.8 & - & 9.2 & 8.1 & 8.7 \\
\hline
\end{tabular}

good device stability, seems to also protect the Pt nanoparticles against iodide reaction, thus preventing the formation of soluble and highly stable iodo-platinate complexes. By contrast, the triiodide diffusion coefficient remains relatively constant during aging. This demonstrates the robustness of the electrolyte under these conditions. Note that, in determining the tri-iodide diffusion coefficient, we assumed that iodine was not consumed.

Complete devices were assembled using a mesoporous "double-layer" configuration of $\mathrm{TiO}_{2}$ sensitized with the heteroleptic ruthenium polypyridyl C106 complex. Regardless of the solvent type, the initial efficiency of this dye was optimized by adopting a transparent layer of $9 \mu \mathrm{m}$ thickness based on $23 \mathrm{~nm}$ anatase $\mathrm{TiO}_{2}$ nanoparticles sheltered by a $5 \mu \mathrm{m}$ thick second light-scattering layer containing $90 \%(\mathrm{w} / \mathrm{w})$ of $400 \mathrm{~nm}$ particles (provided by CCIC) and $10 \%(\mathrm{w} / \mathrm{w})$ of $10 \mathrm{~nm} \mathrm{TiO}_{2}$ nanoparticles. The latter layer acts to effectively backscatter the unabsorbed photons toward the transparent layer, thus enhancing the device's response in the red wavelength range $(650<\lambda<$ $800 \mathrm{~nm})$. Figure 2 compares the evolution of the cell characteristics $\left(V_{\mathrm{oc}} J_{\mathrm{sc}} \mathrm{ff}\right.$, and PCE) for MPN and BN electrolytes up to $1000 \mathrm{~h}$ under $60^{\circ} \mathrm{C} / 100 \mathrm{~mW} \cdot \mathrm{cm}^{-2}$ conditions. At $t=0$, the new $\mathrm{BN}$ electrolyte combines a superior photovoltage $\left(V_{\text {oc }}\right)$ of $\sim 33 \mathrm{mV}$ with a greater fill factor (ff), at the expense of the short-circuit photocurrent $\left(J_{\mathrm{sc}}\right)$, which was $\sim 0.7 \mathrm{~mA} \cdot \mathrm{cm}^{-2}$ lower (Table 1 ). The rate constants corresponding to electron transfer from iodide to $\mathrm{C} 06^{+}$(i.e., dye regeneration) are similar in the two electrolyte

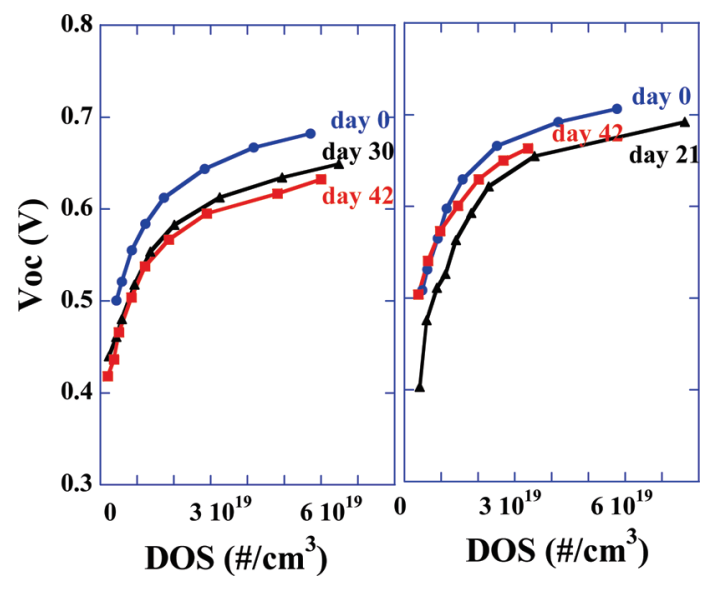

Figure 3. Evolution of the trap states' distribution (DOS) as a function of aging time $\left(60^{\circ} \mathrm{C} / 100 \mathrm{~mW} \cdot \mathrm{cm}^{-2}\right.$ illumination) for MPN (left) and $\mathrm{BN}$ electrolytes (right).

systems, i.e., $1.6 \times 10^{5} \mathrm{~s}^{-1}$ and $1.5 \times 10^{5} \mathrm{~s}^{-1}$ for MPN and BN, respectively. Using a single exponential, this corresponds to halfreaction times of $\sim 6 \mu \mathrm{s}$ for MPN and $\sim 8 \mu \mathrm{s}$ for BN. This parameter is therefore not at the origin of the photocurrent enhancement, nor the charge collection efficiencies, which were also found to be pretty comparable (Supporting Information, Figure S3). As a result, we achieved $\eta=8.8 \%$ PCE using the $\mathrm{BN}$ formulation compared to $\eta=8.5 \%$ PCE when the robust MPN electrolyte was used.

Interestingly, this is not the only advantage of our new electrolyte. Indeed, in the course of this accelerating protocol, the three cell characteristics get even better in comparison to those obtained with the benchmark electrolyte based on MPN. Regardless of the solvent, the photocurrent increases at the expense of the photovoltage, while the fill factor remains relatively constant. Beyond the first 3 days, this decreasing photovoltage compensates the increasing photocurrent for MPN, leading to a constant PCE of $\sim 8.1 \%$. This shows already an excellent PCE 
Table 2

\begin{tabular}{ccccc}
{$\left[\mathrm{Na}^{+}\right]\left(\mathrm{mol} \cdot \mathrm{L}^{-1}\right)$} & $V_{\mathrm{oc}}(\mathrm{mV})$ & $J_{\mathrm{sc}}\left(\mathrm{mA} \cdot \mathrm{cm}^{-2}\right)$ & $\mathrm{ff}$ & PCE $(\%)$ \\
0 & 712 & 15.2 & 0.79 & 8.6 \\
10 & 709 & 16.4 & 0.75 & 8.8 \\
50 & 699 & 17.8 & 0.74 & 9.2 \\
100 & 702 & 18.1 & 0.73 & 9.3 \\
\hline
\end{tabular}

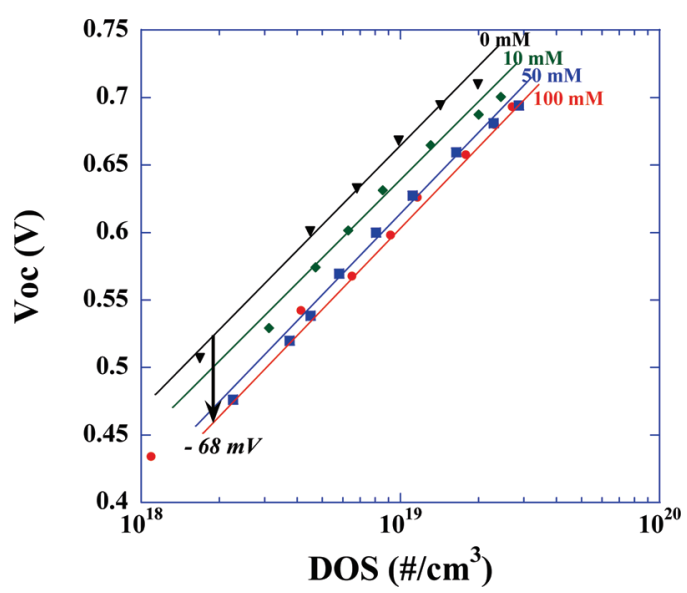

Figure 4. $V_{\text {oc }}$ as a function of trap density (DOS) for C106-sensitized solar cells with $\mathrm{BN}$ electrolyte containing $0-100 \mathrm{mM} \mathrm{NaI}$.

retention of $95 \%$, in agreement with previous reports. ${ }^{18}$ This compensative mechanism between loss of photovoltage and gain of photocurrent contrasts with the case of the BN electrolyte, where the increase of photocurrent is superior to the photovoltage loss. As a result, a maximum PCE of $9.2 \%$ is reached after $350 \mathrm{~h}$ of exposure $\left(V_{\mathrm{oc}}=712 \mathrm{mV}, J_{\mathrm{sc}}=16.9 \mathrm{~mA} \cdot \mathrm{cm}^{-2}\right.$, and $\mathrm{ff}=0.76$ ), before falling to $\eta=8.7 \%$ after $1000 \mathrm{~h}$. Considering the initial vs final PCE, this gives a retention as high as $99 \%$ after $1000 \mathrm{~h}$, and 95\% considering the highest vs final PCE. For both electrolytes, the photovoltage decrease results from a downshift of the trap states' distribution during the thermal/light-soaking accelerating protocol, as suggested by the charge extraction measurements reported in Figure 3. This downshift could favor, to some extent, charge injection as a result of the increased energy gap between the excited state of the dye and the quasiFermi level in $\mathrm{TiO}_{2}$, or it could allow better energy matching between the sensitizer excited states and the acceptor states in $\mathrm{TiO}_{2}$, as reported by Jennings and Wang, ${ }^{3}$ thus explaining the observed photocurrent increase. The origin of this band-edge shift has been explained in the literature on the basis of proton insertion. ${ }^{28}$ Our results suggest that this band-edge movement is less pronounced when butyronitrile is used as solvent.

The above observation illustrates the preponderant role of the distribution and the energetics of these trap states, as they directly control the rates of injection, recombination, and transport. Besides the establishment of an additional dipole moment subsequent to the dye attachment to the $\mathrm{TiO}_{2}$ surface, which could entail a band-edge movement, ${ }^{29}$ the energetic position of these sub-bandgap states can also be tuned by either (i) appropriately modifying the opto-electronic properties of the $\mathrm{TiO}_{2}$ by doping/substituting with a supervalent element (e.g., $\left.\mathrm{Nb}^{5+}\right)^{9}$ or (ii) taking advantage of both the negatively charged surface and the interstitial sites available on the $\mathrm{TiO}_{2}$ surface, which favor

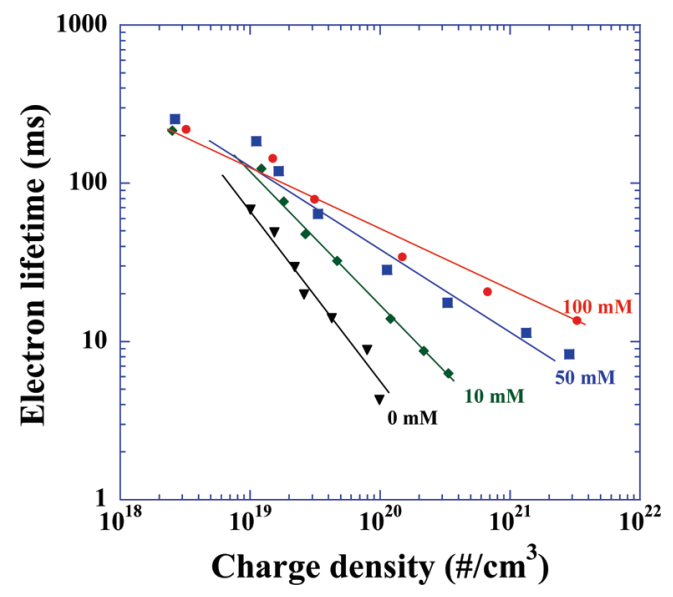

Figure 5. Evolution of electron lifetime as a function of charge density in the film for C106-sensitized solar cells with BN electrolyte containing $0-100 \mathrm{mM}$ NaI.

(a)
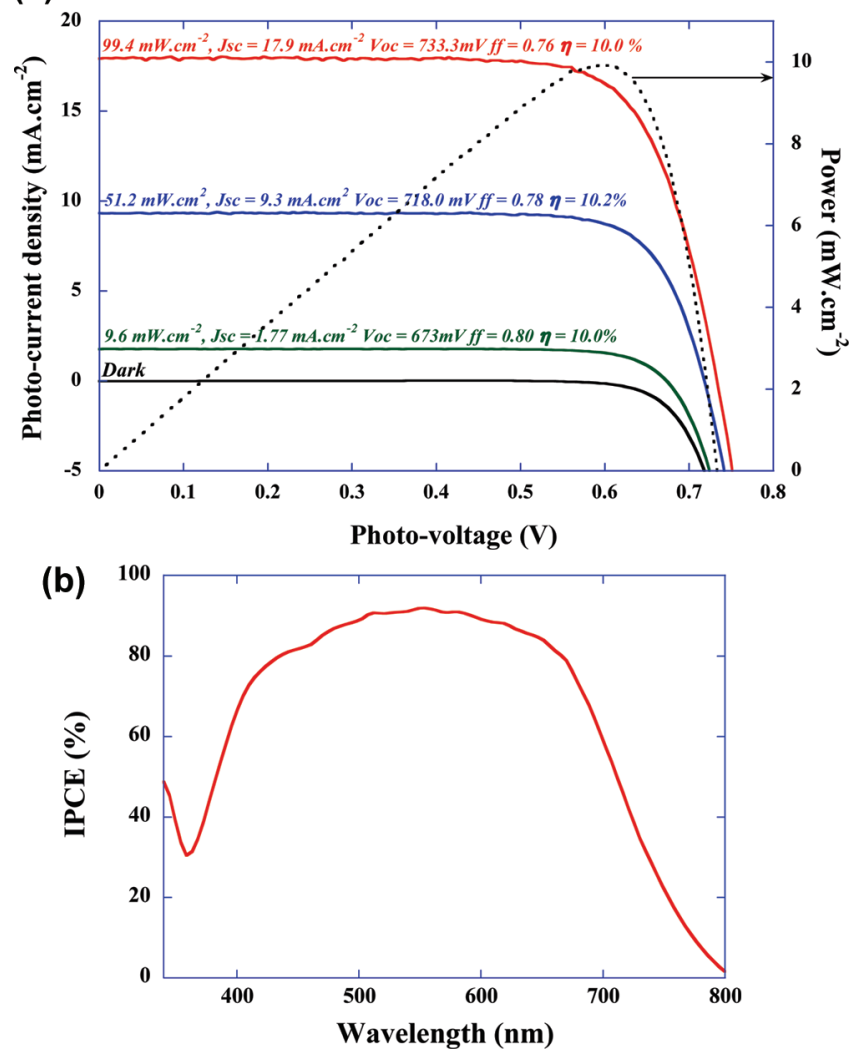

Figure 6. (a) $J-V$ characteristics and (b) IPCE spectrum of C106sensitized solar cells with BN electrolyte containing $50 \mathrm{mM} \mathrm{NaI}$ at 99.4, $51.2,9.6$, and $0 \mathrm{~mW} \cdot \mathrm{cm}^{-2}$ illumination.

specific adsorption of alkali cations. Because $\mathrm{H}^{+}$and $\mathrm{Li}^{+}$are potential-determining ions due to their specific adsorption upon the $\mathrm{TiO}_{2}$ surface, the Fermi-level position in $\mathrm{TiO}_{2}$ is expected to show a Nernst behavior, i.e., downshift as high as $59 \mathrm{mV}$ with increasing concentration of these ions in the electrolyte by 1 order of magnitude. Earlier observations by Franck et al. ${ }^{30}$ and Wang et al. ${ }^{28}$ showed that the lithium inserts into $\mathrm{TiO}_{2}$ during 

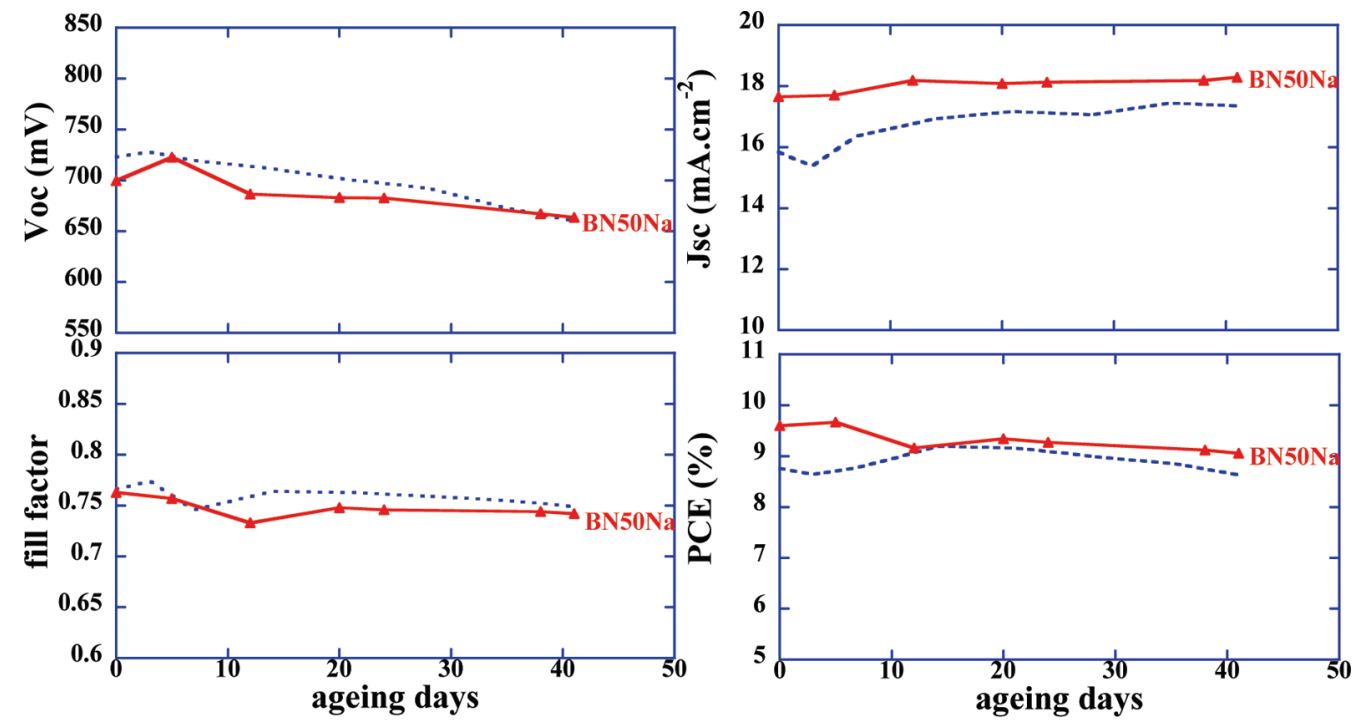

Figure 7. Comparison of the cell characteristics $\left(V_{\mathrm{oc}} J_{\mathrm{sc}} \mathrm{ff}\right.$, and PCE) as a function of time of aging $\left(60{ }^{\circ} \mathrm{C} / 100 \mathrm{~mW} \cdot \mathrm{cm}^{-2}\right.$ illumination $)$ for sodiumfree BN electrolyte (1 M DMII, 0.15 $\left.\mathrm{M} \mathrm{I}_{2}, 0.5 \mathrm{M} \mathrm{NBB}, 0.1 \mathrm{GuNCS}\right)$ and BN electrolyte containing $50 \mathrm{mM} \mathrm{NaI}(\mathrm{BN} 50 \mathrm{Na})$.

illumination. Even though this insertion may pose a risk for longterm stability, Yu et al. recently achieved $92 \%$ stable devices with lithium-containing MPN electrolyte. ${ }^{25}$ In our case, although the lithium-based MPN electrolyte ( $50 \mathrm{mM}$ LiI) gave superior initial efficiencies, it turned out to be detrimental to maintaining a satisfactory stability. In order to overcome this issue by avoiding any insertion path while influencing the energetics of the trap states (in a sub-Nernstian way), we have introduced various concentrations of anhydrous $\mathrm{NaI}$, ranging from 0 to $100 \mathrm{mM}$, within the initial BN electrolyte. Indeed, whereas the anatase polymorph of $\mathrm{TiO}_{2}$ is identified as a class of lithium insertion material, ${ }^{31}$ its crystal structure is not suitable to accommodate sodium ions.

Photovoltaic performance parameters obtained by using a Nabased $\mathrm{BN}$ electrolyte are presented in Table 2 . As expected, the introduction of sodium cation lowers the photovoltage, albeit barely by $10-12 \mathrm{mV}$, representing a loss of only $1.5 \%$. By contrast, the short-circuit photocurrent is remarkably improved by $\sim 20 \%$, from 15.2 to $18.1 \mathrm{~mA} \cdot \mathrm{cm}^{-2}$. This gain is in part compensated by a loss of fill factor value from 79 to $73 \%$. Overall, the introduction of sodium iodide has a markedly favorable effect since it enhances the PCE from $8.6 \%$ to $9.3 \%$.

Interestingly, Figure 4 shows the cell photovoltage as a function of the density of the traps (density of states, DOS). The latter is derived from the cell capacitance measured by the charge extraction technique. ${ }^{32}$ The addition of sodium iodide to the electrolyte does not modify their distribution but only their energetic position, as observed in the case of lithium iodide. ${ }^{32}$ The addition of $100 \mathrm{mM} \mathrm{NaI}$ induces a downshift corresponding to $68 \mathrm{mV}$, which results from the specific adsorption of sodium ion at the $\mathrm{TiO}_{2}$ surface. Interestingly, a lesser decrease in photovoltage is observed under illumination, since the $V_{\mathrm{oc}}$ loss accounts for only $10-12 \mathrm{mV}$. This discrepancy is attributed to the combination of the two other factors responsible for the Fermi-level position, the faster injection rate owing to the greater overpotential for the charge injection, thus providing a way to favor exciton dissociation ${ }^{33}$ and a longer electron lifetime, similar to that experienced when lithium ion is used ${ }^{34}$ (Figure 5). Along this line, we note that the incorporation of sodium salt in electrolyte changes considerably the slope of the linear dependence between electron lifetime (log scale) and charge density (log scale), which refers to a modification in the charge-transfer coefficient $(\alpha)$ related to the mechanism of electron capture by tri-iodide. It shows increasing sodium concentration decreases the $\alpha$ coefficient. The results observed with the C106/sodium ion system are relatively similar to those reported by Kuang et al., who employed the lithium ion-coordinating sensitizers K51.35

In summary, a double-digit PCE has been reached for the first time using a non-volatile electrolyte system. $\mathrm{BN} 50 \mathrm{Na}$ in combination with $\mathrm{C} 106$ shows $10.0 \%$ efficiency under standard A.M. $1.5 \mathrm{G}$ conditions, i.e., $100 \mathrm{~mW} \cdot \mathrm{cm}^{-2}$ illumination $\left(V_{\mathrm{oc}}=\right.$ $733 \mathrm{mV}, J_{\mathrm{sc}}=17.9 \mathrm{~mA} \cdot \mathrm{cm}^{-2}$, and $\left.\mathrm{ff}=0.76\right)$, and even $10.2 \%$ efficiency at $51.2 \mathrm{~mW} \cdot \mathrm{cm}^{-2}\left(V_{\mathrm{oc}}=718 \mathrm{mV}, J_{\mathrm{sc}}=9.3 \mathrm{~mA} \cdot \mathrm{cm}^{-2}\right.$, and $\mathrm{ff}=0.78$ ) (Figure 6a). The spectral response depicts $>80 \%$ quantum efficiency within the range $430-670 \mathrm{~nm}$, attaining a maximum of $\sim 92 \%$ at $550 \mathrm{~nm}$. In contrast to the lithium-based system, we successfully maintained an excellent stability profile for $1000 \mathrm{~h}$ under $60^{\circ} \mathrm{C} / 100 \mathrm{~mW} \cdot \mathrm{cm}^{-2}$ conditions, exhibiting a superior PCE in comparison to that reached with sodium-free electrolyte (Figure 7). After this aging protocol, we achieved $9.1 \% \operatorname{PCE}\left(V_{\mathrm{oc}}=664 \mathrm{mV}, J_{\mathrm{sc}}=18.3 \mathrm{~mA} \cdot \mathrm{cm}^{-2}\right.$ and $\left.\mathrm{ff}=0.74\right)$, leading to as high as 95\% PCE retention. The loss in the conversion efficiency arises mainly from the decline of $V_{\mathrm{oc}}$ even though part of this loss is compensated by a gain in photocurrent, suggesting a downshift of the intraband energy states. Finally, based on this new electrolyte formulation, excellent results in terms of PCE and/or stability were also obtained in association with other sensitizers, namely B11, C103, and the porphyrin YD2, thus underlining the broad applicability of this new electrolyte system (Supporting Information, Figure S4)

\section{CONCLUSION}

We have reported in this work the elaboration of a new, highly performing electrolyte formulation based on butyronitrile as a solvent. This new class of electrolyte offers higher efficiency and higher stability in comparison to the benchmark 3-methoxypropionitrile-based electrolyte. After optimizing relative concentrations between additives, we demonstrated that 
the addition of sodium ion enables control, in a sub-Nernstian manner, the energetics of the trap states in order to optimize the electron injection rate without sacrificing cell stability. As a result, in combination with the high molar extinction coefficient C106 dye, we achieved for the first time double-digit efficiency with a non-volatile electrolyte, namely $10.0 \%$ under A.M. $1.5 \mathrm{G}$ $100 \mathrm{~mW} \cdot \mathrm{cm}^{-2}$ illumination, and even $10.2 \%$ at $51.2 \mathrm{~mW} \cdot \mathrm{cm}^{-2}$. Remarkable stability properties have been obtained, i.e., a PCE retention above $95 \%$ after $1000 \mathrm{~h}$ of $100 \mathrm{~mW} \cdot \mathrm{cm}^{-2}$ light exposure at $60{ }^{\circ} \mathrm{C}$ thermal stress. We showed with $\mathrm{BN} 50 \mathrm{Na}$ formulation $9.1 \%$ PCE upheld after a $60{ }^{\circ} \mathrm{C} / 1$ sun light-soaking protocol.

\section{EXPERIMENTAL SECTION}

Materials. All solvents and reagents were of puriss grade quality and carefully stored within Ar-filled glovebox. The reagents were used as received while the solvents were double-distilled prior using. The GuNCS was purchased from Fluka. DMII was prepared accordingly to a reported procedure. ${ }^{36}$

Device Preparation. A double-layer film of interconnected mesoporous anatase $\mathrm{TiO}_{2}$ particles was prepared by a screen-printing method upon $4 \mathrm{~mm}$ thick NSG10 TCO glass (Nippon Sheet Glass). The procedure for paste preparation and screen-printing the electrodes has been reported. ${ }^{37}$ The film was sensitized for $14 \mathrm{~h}$ in darkness within a dye solution of 1:1 volume ratio of tert-butanol and acetonitrile containing $300 \mu \mathrm{M} \mathrm{C106}$ and $50 \mu \mathrm{M} 4$-guanidinobutyric acid as co-adsorbant. After being washed with acetonitrile, the sensitized electrodes were sealed using a $25 \mu \mathrm{m}$ thick Surlyn gasket, melted by heating with a Pt-loaded TEC7 TCO counter electrode. This same glass was used for the symmetric cells $\mathrm{TCO}-\mathrm{Pt} /$ electrolyte/Pt-TCO. The $\mathrm{Pt}$ was prepared by thermal degradation at $400{ }^{\circ} \mathrm{C}$ for $15 \mathrm{~min}$ in air of a drop based on $5 \mathrm{mM}\left(\mathrm{H}_{2} \mathrm{PtCl}_{6}\right)_{\mathrm{EtOH}}$ cast on the TCO surface. The internal space between the two electrodes was backfilled by electrolyte using a vacuumfilling system. A hole was introduced in the counter electrode side by sand-blasting and was afterward sealed with a glass sheet. The Z946 electrolyte's composition is $1 \mathrm{M} \mathrm{DMII}, 0.15 \mathrm{M} \mathrm{I}_{2}, 0.5 \mathrm{M} \mathrm{NBB}$, and $0.1 \mathrm{M}$ GuNCS in MPN solvent. The BN and BN50Na composition is equivalent to that for Z946, except that the solvent is based on butyronitrile and contains in addition $50 \mathrm{mM} \mathrm{NaI}$ for the second denomination.

The printed photoanode has a spot geometry with a surface area of $0.283 \mathrm{~cm}^{2}$. Prior to measurements, the cell was masked with an aperture of $0.159 \mathrm{~cm}^{2}$. An anti-reflective coating on the NSG10 glass was also used to prevent reflection losses, and the cell was double-sealed with thermosetting Torrseal polymer to prevent water penetration during aging.

Photovoltaic Measurements. A $450 \mathrm{~W}$ xenon light source (Oriel, USA) was used to provide an incident irradiance of $100 \mathrm{~mW} \cdot \mathrm{cm}^{-2}$ at the surface of the solar cells. The spectral output of the lamp was filtered using a Schott K113 Tempax sunlight filter (Präzisions Glas \& Optik $\mathrm{GmbH}$, Germany) that lets through light from 350 to $750 \mathrm{~nm}$ and hence reduces the light mismatch between real solar illumination and the simulated one to $<2 \%$. Light intensities were regulated with wire mesh attenuators. The $J-V$ measurements were performed using a Keithley model 2400 digital source meter (Keithley, USA) by applying an independent external voltage to the cell and measuring the photogenerated current exiting the cell. Incident photon-to-current conversion measurements were realized using a $300 \mathrm{~W}$ xenon light source (ILC Technology, USA). A Gemini-180 double-monochromator from Jobin Yvon Ltd. (UK) was used to select and increment wavelength irradiation to the cell. Monochromatic incident light was passed through a chopper running at $1 \mathrm{~Hz}$ frequency, and the on/off ratio was measured by using an operational amplifier. This was superimposed on a white-light bias corresponding to $10 \mathrm{~mW} \cdot \mathrm{cm}^{-2}$ intensity.

The electron lifetime was measured by transient photovoltage decay measurements at open circuit. The white-light bias, used to control the charge density within the mesoporous film, was generated by an array of LEDs, while a pulsed red light ( $0.05 \mathrm{~s}$ square pulse width) was controlled by a fast solid-state switch to ensure close-to-equilibrium light perturbation. The subsequent voltage (at open-circuit) and current decay (at shortcircuit) were recorded on a Mac-interfaced Keithley 2602 source meter. These millisecond range decays were simulated by a single exponential to extract the rate constants for electron recombination (from the voltage decay) and the electron transport at short-circuit.

\section{ASSOCIATED CONTENT}

S Supporting Information. Evolution during aging of the charge-transfer resistance at $60{ }^{\circ} \mathrm{C}$ in the dark for MPN electrolyte; nanosecond transient absorbance spectroscopy measurements applied to the oxidized C106 dye species in either redox couple-free, BN, or MPN electrolytes; comparison of the charge collection efficiency between BN and MPN electrolytes; and PV characteristics recorded with other sensitizer systems. This material is available free of charge via the Internet at http://pubs.acs.org.

\section{AUTHOR INFORMATION}

\section{Corresponding Authors}

frederic.sauvage@u-picardie.fr; michael.graetzel@epfl.ch

\section{ACKNOWLEDGMENT}

This research was carried out within the EC project "Robust DSC" (grant, agreement no. 212792). A.M., J.-E.M., and M.G. are grateful to the Swiss National Science Foundation for support. The authors thank Dyesol for graciously supplying $\mathrm{TiO}_{2}$ colloids, Aravind Kumar Chandiran for optimizing the co-adsorbant nature and its concentration with C106, Dr. Robin Humphry-Baker and Dr. Shaik Zakeeruddin for fruitful discussions, and Prof. Peng Wang for kindly providing the C106 dye. S.C. is indebted to a Chimie Paristech fellowship.

\section{REFERENCES}

(1) O’Regan, B.; Graetzel, M. Nature 1991, 353, 737.

(2) Willis, R. L.; Olson, C.; O’Regan, B.; Lutz, T.; Nelson, J.; Durrant, J. R. J. Phys. Chem. B 2002, 106, 7605-7613.

(3) Jennings, J. R.; Wang, Q. J. Phys. Chem. C 2010, 114, 1715-1724.

(4) Graetzel, M. Inorg. Chem. 2005, 44, 6841-6851.

(5) Goldstein, J.; Yakupov, I.; Breen, B. Solar Energy Mater. Solar Cells 2010, 94, 638-641.

(6) Pichot, F.; Pitts, J.-R.; Gregg, B. A. Langmuir 2000, 16, 5626-5630.

(7) Lengo, C.; Nogueira, A. F.; De Paoli, M. A.; Cachet, H. J. Phys. Chem. B 2002, 106, 5925-5930.

(8) Ito, S.; Cevey, N.; Rothenburger, G.; Liska, P.; Comte, P.; Zakeeruddin, S. M.; Pechy, P.; Nazeeruddin, Md. K.; Graetzel, M. Chem. Commun. 2006, 4004-4006.

(9) Chandiram, A. K.; Sauvage, F.; Casas-Cabanas, M.; Comte, P.; Graetzel, M. J. Phys. Chem. C 2010, 114, 15849-15856.

(10) Ito, S.; Zakeeruddin, S. M.; Comte, P.; Liska, P.; Kuang, D.; Graetzel, M. Nat. Photonics 2008, 2, 693-698.

(11) Chiba, Y.; Islam, A.; Watanabe, Y.; Komiya, R.; Koide, N. L.; Han, L. Jpn. J. Appl. Phys. 2006, 45, L638-640. 
(12) Gao, F.; Wang, Y.; Shi, D.; Zhang, J.; Wang, M.; Jing, X.; Humphry-Baker, R.; Wang, P.; Zakeeruddin, S. M.; Graetzel, M. J. Am. Chem. Soc. 2008, 130, 10720-10728.

(13) Cao, Y.; Bai, Y.; Yu, Q.; Cheng, Y.; Liu, S.; Shi, D.; Gao, F.; Wang, P. J. Phys. Chem. C 2009, 113, 6290-6297.

(14) Chen, C. Y.; Wang, M.; Li, J.Y.; Pootrakulchote, N.; Alibabaei, L.; Cevey, N.; Decoppet, J.-D.; Tsai, J.; Graetzel, C.; Wu, C.; Zakeeruddin, S. M.; Graetzel, M. ACS Nano 2009, 3, 3103-3109.

(15) Sauvage, F.; Decoppet, J.-D.; Zhang, M.; Zakeeruddin, S. M.; Comte, P.; Nazeeruddin, M. K.; Wang, P.; Graetzel, M. J. Am. Chem. Soc. 2011, 133, 9304-9310.

(16) Bessho, T.; Zakeeruddin, S. M.; Yeh, C. Y.; Diau, E.; Graetzel, M. Angew. Chem. 2010, 49, 6646-6649.

(17) Noda K. Presented at the DSC-IC Conference, Nov 1-4, 2010, Colorado Springs, USA.

(18) Kuang, D.; Klein, C.; Ito, S.; Moser, J. E.; Humphry-Baker, R.; Evan, N.; Duriaux, F.; Graetzel, C.; Zakeeruddin, S. M.; Graetzel, M. Adv. Mater. 2007, 19, 1133-1137.

(19) Wang, P.; Zakeeruddin, S. M.; Exnar, I.; Graetzel, M. Chem. Commun. 2002, 2972-2973.

(20) Wang, P.; Zakeeruddin, S. M.; Moser, J. E.; Nazeeruddin, Md. K.; Sekiguchi, T.; Graetzel, M. Nat. Mater. 2003, 2, 402-407.

(21) Yang, C.; Ho, W.; Yang, H.; Hsuch, M. J. J. Mater. Chem. 2010, 20, 6080-6085.

(22) Cao, Y.; Zhang, J.; Bai, Y.; Li, R.; Zakeeruddin, S. M.; Graetzel, M.; Wang, P. J. Phys. Chem. C 2008, 112, 13775-13781.

(23) Bai, Y.; Cao, Y.; Zhang, J.; Wang, M.; Li, R.; Wang, P.; Zakeeruddin, S. M.; Graetzel, M. Nat. Mater. 2008, 7, 626-630.

(24) Shi, D.; Pootrakulchote, N.; Li, R.; Guo, J.; Wang, Y.; Zakeeruddin, S. M.; Graetzel, M.; Wang, P. J. Phys. Chem C 2008, 112, 17046-17050.

(25) Yu, Q.; Zhou, D.; Shi, Y.; Si, X.; Wang, Y.; Wang, P. Energy Environ. Sci. 2010, 3, 1722-1725.

(26) Haush, A.; Georg, A. Electrochim. Acta 2001, 3457-3466.

(27) MacDonald, J.-R. Impedance Spectroscopy; Wiley: New-York, 1987.

(28) Wang, Q.; Zhang, Z.; Zakeeruddin, S. M.; Graetzel, M. J. Phys. Chem. C 2008, 112, 7084-7092.

(29) De Angelis, F.; Fantacci, S.; Selloni, A.; Graetzel, M.; Nazeeruddin, M. K. Nano Lett. 2007, 7, 3189-3195.

(30) Kopidakis; Benkstein, K. D.; Van de Lagemaat, J.; Frank, A. J. J. Phys. Chem. B 2003, 107, 11307-11315.

(31) Sudant, G.; Baudrin, E.; Larcher, D.; Tarascon, J.-M. J. Mater. Chem. 2005, 15, 1263-1269.

(32) O’Regan, B.; Durrant, J. R.; Sommeling, P. M.; Bakker, N. J. J. Phys. Chem. C 2007, 111, 14001-14010.

(33) Koops, S. E.; O’Regan, B.; Barnes, P. R. F.; Durrant, J. R. J. Am. Chem. Soc. 2009, 131, 4808-4818.

(34) Yu, Q.; Wang, Y.; Yi, Z.; Zu, N.; Zhang, J.; Zhang, M.; Wang, P. ACS Nano 2010, 4, 6032-6038.

(35) Kuang, D.; Klein, C.; Snaith, H. J.; Moser, J. E.; Humphry-Baker, R.; Comte, P.; Zakeeruddin, S. M.; Graetzel, M. Nano Lett. 2006, 6, 769-773.

(36) Bando, K. K.; Mitsuzuka, Y.; Sugino, M.; Sugihara, H.; Sayama, K.; Arakawa, H. Chem. Lett. 1999, 853.

(37) Ito, S.; Murakami, T. N.; Comte, P.; Liska, P.; Graetzel, C.; Nazeeruddin, M. K.; Graetzel, M. Thin Solid Film 2008, 516, 4613-4619. 


\section{Butyronitrile-based electrolyte for dye-sensitized solar cells}

Frédéric SAUVAGE ${ }^{1-2} *$, Sarine $\mathrm{CHHOR}^{1}$, Arianna MARCHIORO ${ }^{1}$, Jacques-E. MOSER ${ }^{1}$, Michael GRAETZEL ${ }^{1 *}$

${ }^{1}$ Laboratoire de Photonique et Interfaces, Institut des Sciences et Ingénierie Chimiques, Ecole Polytechnique Fédérale de Lausanne (EPFL), Station 6, CH-1015, Lausanne, Switzerland. ${ }^{2}$ Laboratoire de Réactivité et Chimie des Solides, Université de Picardie Jules Verne, CNRS UMR6007, 33 rue Saint-Leu, F-80039 Amiens Cedex, France.

Fig. S1: Evolution of the charge transfer resistance for MPN electrolyte as a function of time of ageing at $60^{\circ} \mathrm{C}$ under dark conditions.

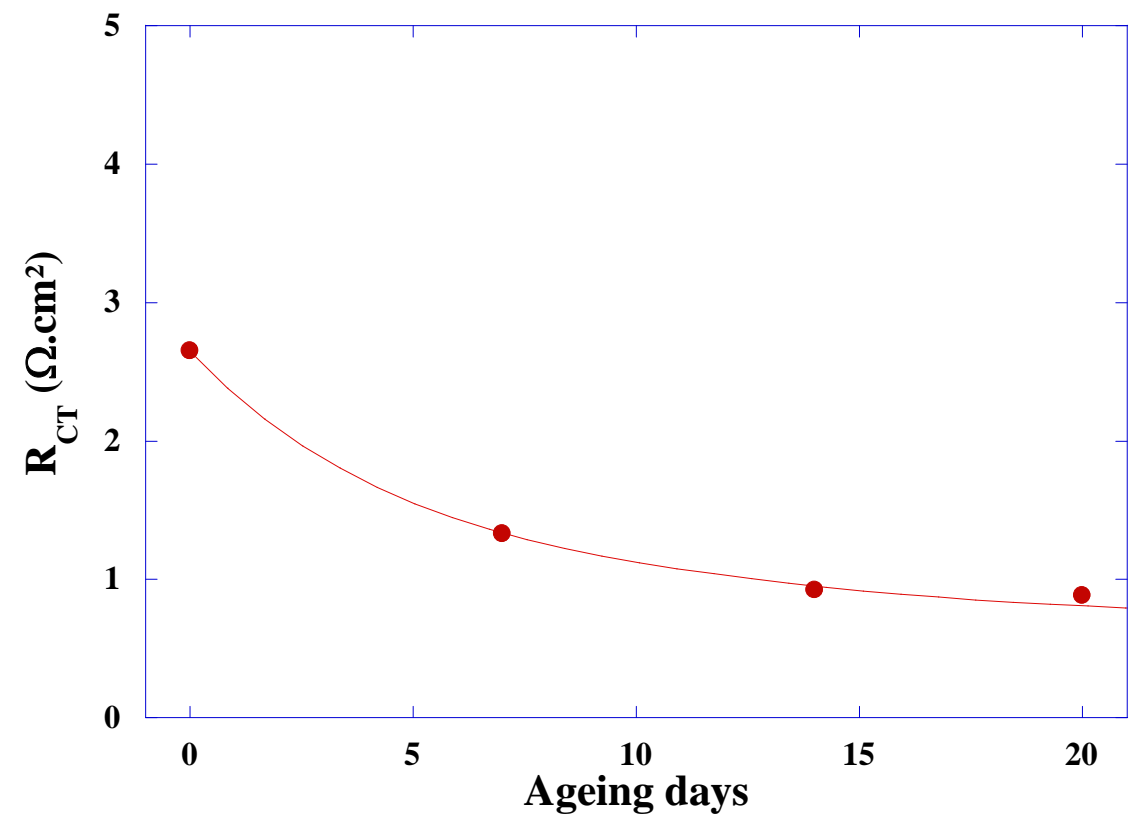

SAUVAGE et al. : Figure S1 


\section{Experimental: Nanosecond Laser Transient Absorbance Measurements}

Dye-loaded, $7 \mu$ m-thick, nanocrystalline $\mathrm{TiO}_{2}$ films were excited by nanosecond laser pulses produced by a frequency-tripled Q-switched Nd:YAG laser (Continuum Surelight, $20 \mathrm{~Hz}$ repetition rate) pumping an optical parametric oscillator (GWU OPO-355). The output of the OPO was tuned at $\lambda=520 \mathrm{~nm}$ ( $5 \mathrm{~ns}$ fwhm pulse duration). The beam was attenuated to a fluence of less than $30 \mu \mathrm{J} / \mathrm{cm}^{2}$ per pulse to avoid undesirable effects of higher laser intensities. The probe light from a xenon arc lamp was passed through a monochromator and focused onto the sample. A second monochromator was placed after the sample to prevent laser light scattered by the sample from reaching the detector. The probe signal was set at a wavelength of $\lambda=715 \mathrm{~nm}$ which corresponds to the oxidized state absorbance of the $(\mathrm{C} 106)^{+}$as deduced from Photo-Induced Absorption technique and in agreement with previously recorded transient absorption spectra ${ }^{1}$. The transient decay observed corresponds to the C106 oxidized state lifetime in presence or not of redox species $\left(\mathrm{I}_{3}{ }^{-} / \mathrm{I}^{-}\right)$. The probe beam intensity changes were finally measured by a fast photomultiplier tube and recorded by a digital oscilloscope. Signals used to calculate the time-evolution of transient absorption were typically averaged over 3000 consecutive laser shots. 
Fig. S2: Temporal profiles of the transient absorbance measured at $715 \mathrm{~nm}$ upon pulsed laser excitation (520 nm wavelength, 5ns full width half-maximum pulse duration, $<30 \mu \mathrm{J} / \mathrm{cm}^{2}$ pulse fluence, $20 \mathrm{~Hz}$ repetition rate) of samples comprised of C106 dye adsorbed on nanocrystalline $\mathrm{TiO}_{2}$ films in a redox-inactive electrolyte (green trace) and in BN and MPN electrolytes (red and purple traces, respectively) in open-circuit conditions. Smooth solid lines shown are mono-exponential fits of noisy experimental data.

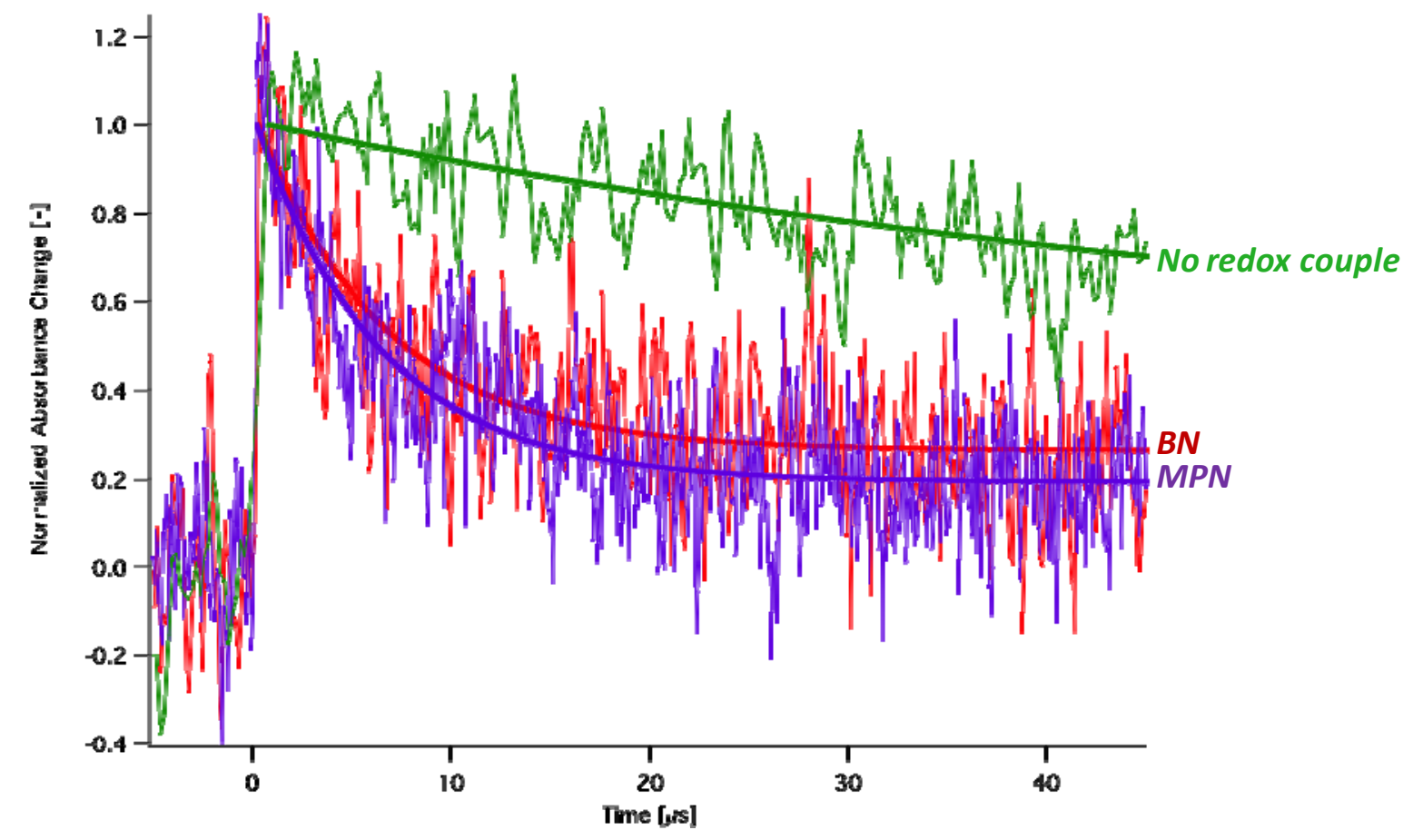

SAUVAGE et al. : Figure S2 
Fig. S3: Evolution of the charge collection efficiency as a function of charge density comparing the MPN with the BN electrolyte. The charge collection efficiency $\left(\eta_{\mathrm{CE}}\right)$ was determined by analysis of the photo-voltage and photo-current transient decay yielding to the recombination rate constant $\left(\mathrm{k}_{\mathrm{rec}}\right)$ and the sum of recombination and transport rates $\left(\mathrm{k}_{\text {trans }}\right)$, respectively. For this, we used the following relationship: $\eta_{C E}=\frac{\boldsymbol{k}_{\text {rec }}}{\boldsymbol{k}_{\text {rec }}+\boldsymbol{k}_{\text {trans }}}$.

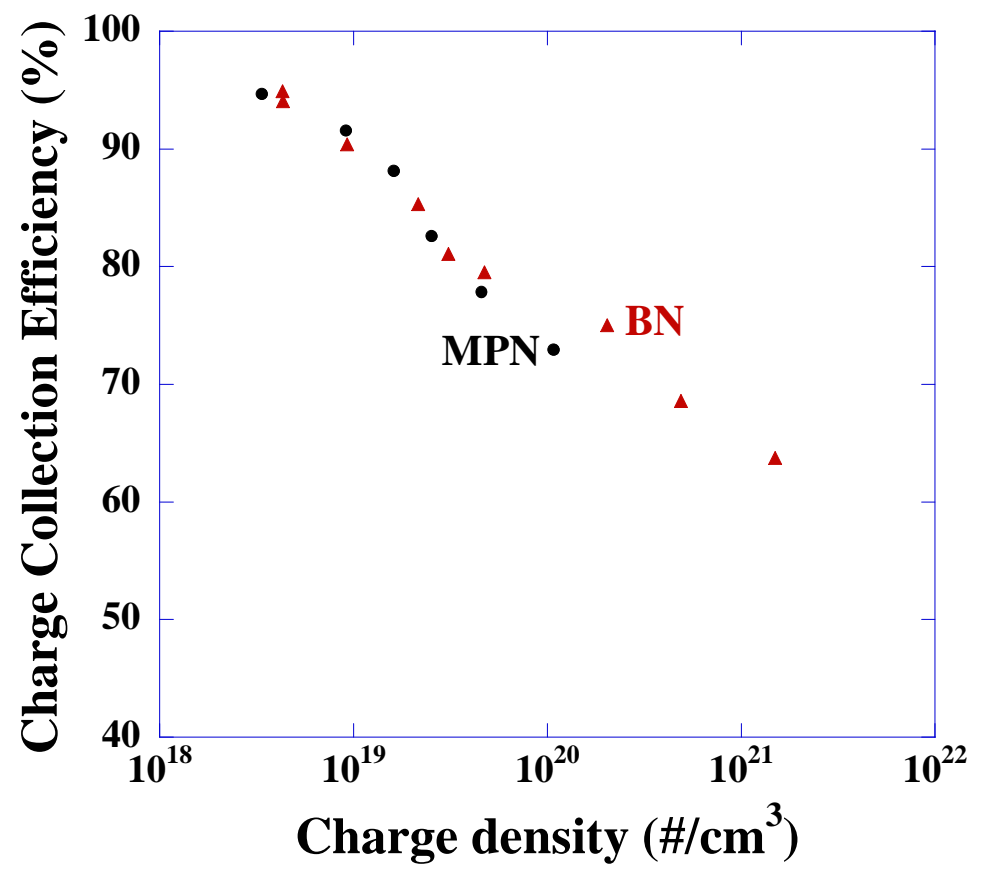

SAUVAGE et al. : Figure S3 
Fig. S4: (J-V) characteristics using BN electrolyte containing $50 \mathrm{mM}$ of $\mathrm{NaI}$ in association with (a) C106 Dinhop 4:1 ratio (b) B11 Dinhop 4:1 ratio ${ }^{2}$ (c) C103 Cheno 1:1 $\mathrm{ratio}^{3}$ and (d) YD2 dyes ${ }^{4}$. PCE retention after $60^{\circ} \mathrm{C}-100 \mathrm{~mW} / \mathrm{cm}^{2}$ light soaking stress is indicated in inset. Dye structure and opto-electronic properties are reported in the above mentioned reference.

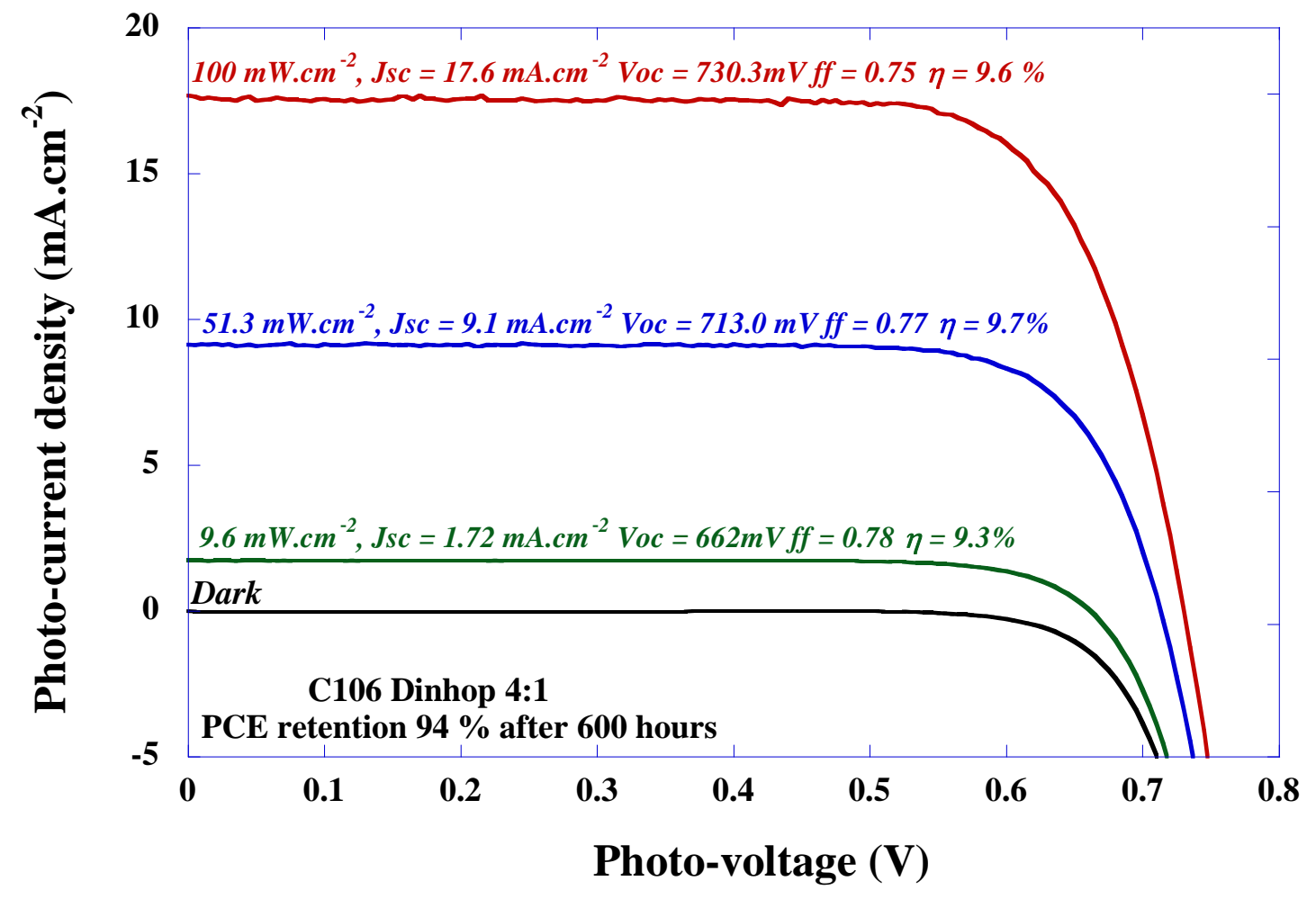

SAUVAGE et al. : Figure S4(a) 


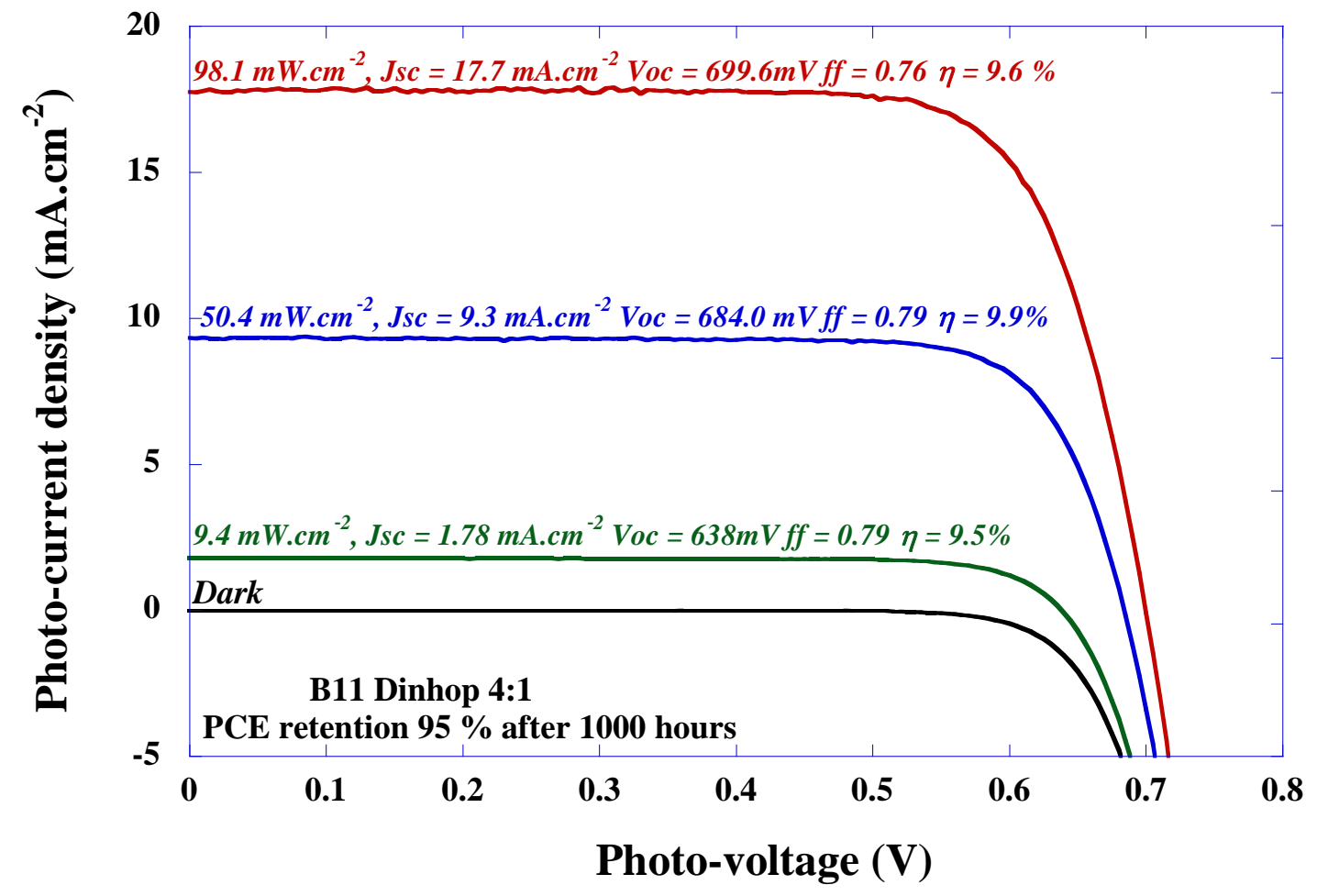

SAUVAGE et al. : Figure S4(b) 


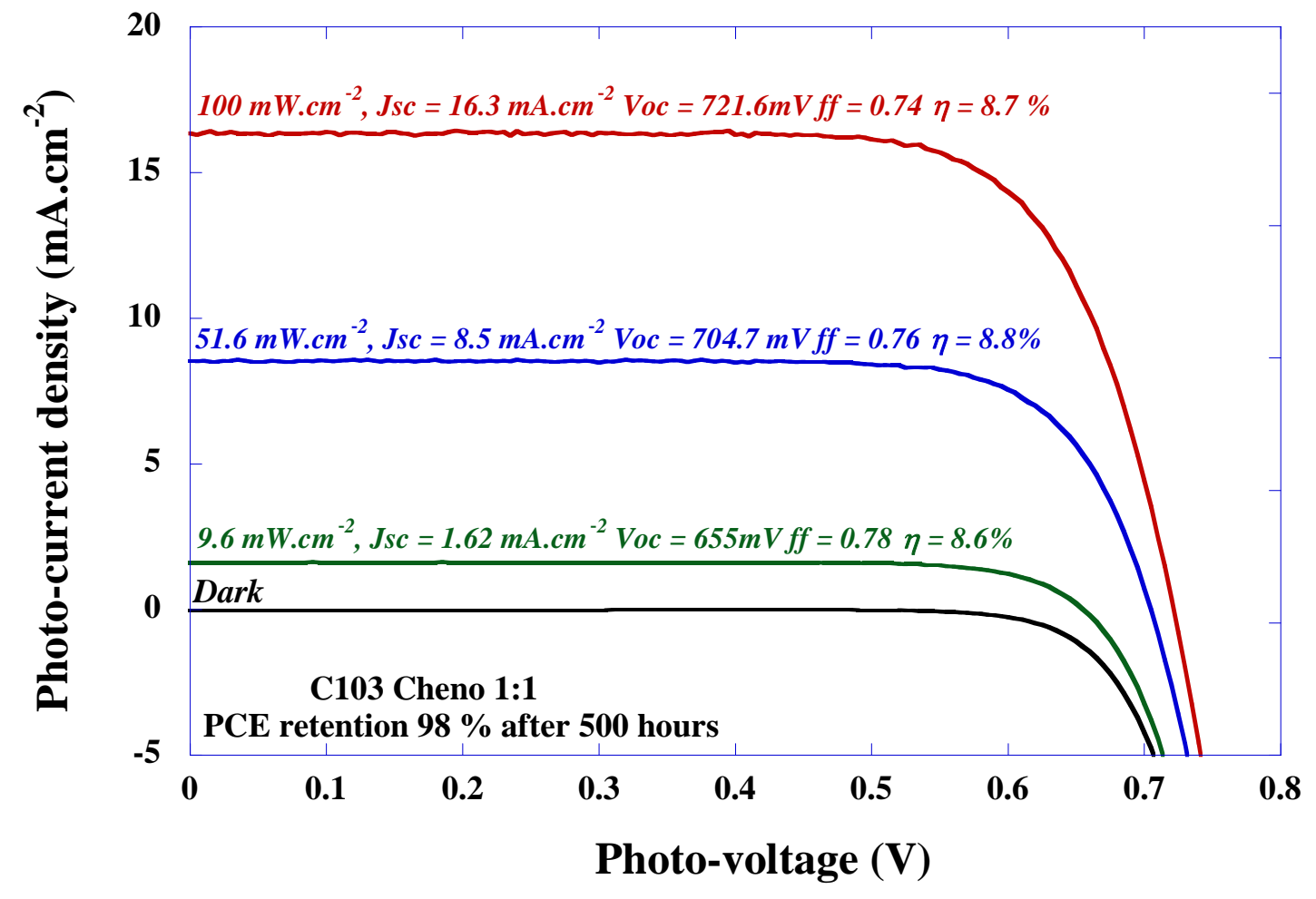

SAUVAGE et al. : Figure S4(c) 


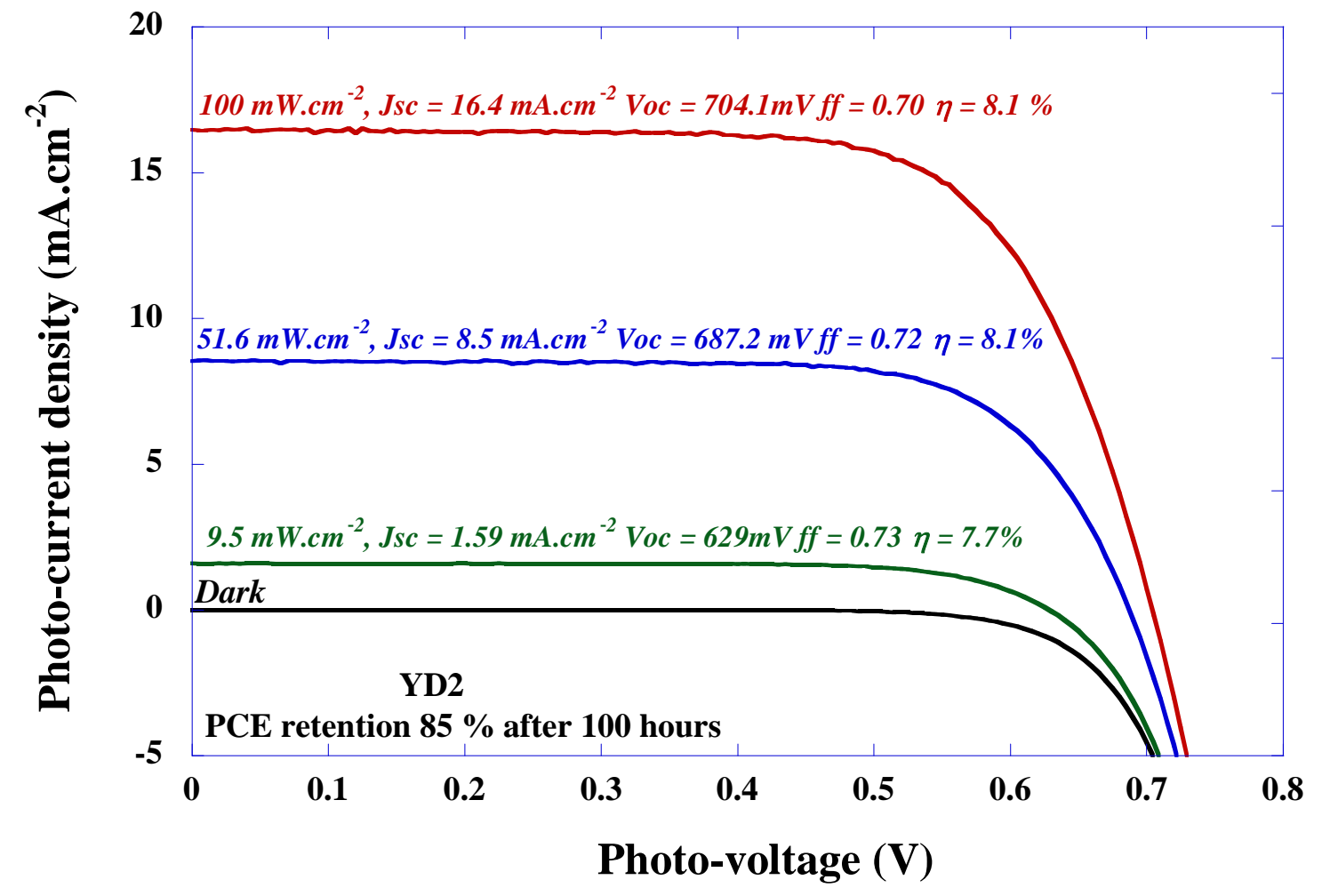

SAUVAGE et al. : Figure S4(d) 


\section{Bibliography}

[1] Yu Q., Zhou D., Shi Y., Si X., Wang Y., Wang P., Energy Environ. Sci. 2010, 3, 17221725

[2] Chen C.Y., Wang M., Li J.Y., Pootrakulchote N., Alibabaei L., Cevey N., Decoppet J.-D., Tsai J., Graetzel C., Wu C., Zakeeruddin S.M., Graetzel M., ACSNano 2009, 3(10), 31033109

[3] Cao Y., Bai Y., Yu Q., Cheng Y., Liu S., Shi D., Gao F., Wang P., J. Phys. Chem. C 2009, 113(15), 6290-6297

[4] Bessho T., Zakeeruddin S.M., Yeh C.Y., Diau E., Graetzel M., Angew. Chem. 2010, 49, 6646-6649 